\title{
COVID-19 Pandemic: Lethal and Non-lethal Drifts
}

\author{
Umberto Cornelli
}

\section{ABSTRACT}

Background: The ratio positive cases/deaths due to COVID-19 in the World is very variable since there are countries that differ up to two orders of magnitude.

Objective: To analyze the positive/deaths ratio up to May 24, 2021, in the European countries on the light of asymptomatic subjects and determine if the presence of non-mortal drifts can justify the present deaths decay.

\begin{abstract}
Methods: The data of the European countries were retrieved from the WHO coronavirus dashboard. Italy was taken as example to calculate the differences among regions in the same country, and the relative data were taken from the Official Bulletin. Statistical analysis was based on the ODDS ratio.
\end{abstract}

Results: True asymptomatic subjects are difficult to be calculated and the differences among the deaths ratio can be due to the presence of non-mortal drifts.

Conclusions: The non-mortal drift should be considered as one of the reasons of the present death decay, and vaccinations can accelerate this process.

Keywords: COVID-19; non mortal drifts; COVID-19 death ratio; COVOID19 European countries.

\section{INTRODUCTION}

The Coronavirus belongs to the Riboviria realm, Orthornavirae kingdom, Pisuviricota phylum, Pisoniviricetes class, Nidovirales order, Cornidovirineae suborder, Coronaviridae family, Orthocoronavirinae subfamily. The first coronavirus was identified in the mid1960s and was characterized by a positive strand of RNA, with a helically symmetrical nucleocapsid. The name in part derives from the viral surface, which looks similar to a solar corona. Coronaviruses phylogenetically belong to four distinct taxonomic groups labelled alpha, beta, gamma, and delta $(\alpha, \beta, \gamma$ and $\delta)$, where those that affect humans are types alpha and beta. Alpha causes the common cold and beta, respiratory diseases [1].

The four groups are found in many species from mammals (such as cats, dogs, bovines, bats, and camels) to birds, and may cause respiratory and enteric diseases.

Coronaviruses, such as $\mathrm{HCoV}-229 \mathrm{E}$ and HCov-OC43, have long been known to circulate in the human population, and they - together with the more recently identified $\mathrm{HCoV}$ NL63 and HCov-HKU1 - cause seasonal, usually mild respiratory tract infections associated with the symptoms of the common cold [2].

The most severe diseases are caused by the beta coronaviruses in the form of SARS (severe acute respiratory syndrome), which is caused by SARS Cov, SARSs CiCov, SARS CovCFB, and MERS-Cov (middle east respiratory syndrome).

SARS started out in China (Guangdong region) in 2002 and spread to 29 other countries killing about $10 \%$ of infected
Submitted : June 04, 2021

Published : June 26, 2021

ISSN: $2593-8339$

DOI: 10.24018 / ejmed.2021.3.3.915

Umberto Cornelli*

Loyola University School of Medicine, Chicago, USA.

(e-mail: ucornelli@gmail.com)

*Corresponding Author people (a total of 813 deaths) [1]. Studies into the disease point to civets, sold in the local wet market, as probable carriers of the virus.

The theory behind its appearance was readily connected to the rapid economic growth in Southern China. This has led among other things to an increase in demand for exotic game food, such as bats and pangolins, which are sold in wet markets. These animals are kept in overcrowded cages, without biosecurity. The jump (spillover) of this novel virus from animals to humans was followed by human-to-human transmission, and over 8000 people were affected in 27 countries in just a few months in early 2003 with a death rate of about $10 \%$. In late 2003 , there was a small re-emergence and the discovery of a very similar virus in horseshoe bats.

In 2007, SARS was considered "an agent of emerging and reemerging infections" [3] and the clear indications were that "the presence of a large reservoir of SARS-CoV-like viruses in horseshoe bats, together with the culture of eating exotic animals in southern China, is a time bomb."

This was a warning that should have been taken seriously. The next viral infection of animal origin appeared in 2012 : MERS.

MERS started in Arabia (Jeddah) and was considered closely related to SARS, although less transmissible since it spread to fewer than 10 countries causing only 322 deaths.

In this case, the carrier was thought to be the dromedary camel [4] but also the horseshoe bat [5]. Since it has been known for almost 15 years that coronaviruses undergo genetic recombination [6], a drift towards more aggressive forms was predictable and regularly happens, although the zoonotic source of their transmission is not yet clear.

During December 2019, clusters of patients with atypical 
pneumonia were reported by local health facilities in Wuhan, and the patients were found to be epidemiologically linked to the animal and seafood wholesale wet market in the city. Later, in January 2020, the first fatality was reported [7]. During the first 6 weeks of the outbreak, several cases were reported in more than 37 countries. The rapid increase suggested that the virus was transmitted through the faecaloral route and aerosol formation. Furthermore, it very often spread asymptomatically. To overcome this problem, complete quarantine was necessary to allow infected people to develop symptoms without spreading the virus.

The coronavirus's ability to evolve quickly, together with the spread of possible variants in animal species (wild or domestic), make a common research effort necessary throughout the world.

Research should also be carried out into isolating strains which may escape from laboratories despite all the security measures in place. However, there are currently no alternatives to "viral isolation". As in the case of nuclear power stations, even if we apply all precautions to prevent environmental contamination, something unpredictable may occur.

This does not mean that Covid-19 is an example of this. Although its genome was only sequenced in January 2020, we cannot rule out that the virus had already spread before that date.

One important aspect we should focus on are asymptomatic cases.

Initially, in a study conducted in Wuhan on 10 million people, there was no evidence of asymptomatic transmission [8].

Nevertheless, this was not confirmed by other authors, and it was estimated that up to $80 \%$ of infections were asymptomatic. This figure has now been revised down to between $17 \%$ and $20 \%[9,10]$.

However, the real problem is to identify "true" asymptomatic subjects. When some cases were followed in hospital after a positive swab [11], it became evident that there are at least four classes of asymptomatic subject:

a) "True" asymptomatic subjects, who have a positive swab, never develop signs (e.g., radiographic lung abnormalities and abnormal test results) or symptoms (e.g., fever, diarrhoea and changes in taste or smell), and later have a negative swab.

b) Asymptomatic subjects who have signs which can only be seen through radiography and laboratory analyses, but who do not show symptoms.

c) Subjects "in the incubation stage", who will develop signs and/or symptoms in the next few days.

d) Subjects who are "over the disease", which was subclinical or mild, but still have a positive swab.

All these aspects make it hard to calculate a precise figure for the number of "real" asymptomatic subjects and judge the relevant immunological characteristics which are consistent with protection.

Immunological assessment was carried out on subjects who were presumed to be asymptomatic and on symptomatic patients with different degrees of severity. It highlighted a complex reaction mechanism [12] which primarily leads to a decrease in T lymphocytes (particularly $\mathrm{CD} 4^{+}$and $\mathrm{CD} 8^{+}$) and in INF- $\gamma$ interferon production in symptomatic patients.
Some authors showed that $\mathrm{T}$ lymphocytes and $\mathrm{T}$ cell receptors are altered, and the complement pathway is also stimulated [13]. B lymphocytes and B cell receptors are also altered, and it seems that the immunological response determined by $\mathrm{T}$ cells and $\mathrm{B}$ cells is well coupled in asymptomatic subjects. If humoral immunity becomes uncoupled as the disease progresses, there is a decrease in interferon production, causing TNF- $\gamma$ to be extremely low in symptomatic patients.

Despite plasmablast and plasma cell expansion, the $\operatorname{Ig} \mathrm{A} 2$ which protects mucous cells decreases.

A study carried out on 37 asymptomatic subjects (without symptoms for the 14 days preceding hospitalization) and on the same number of symptomatic patients revealed some peculiar aspects [14]. Only 16 asymptomatic subjects showed no abnormality under radiological examination (such as ground-glass opacities, stripe shadows and diffuse consolidation), and laboratory tests showed that only 16 cases (not the same ones) had completely normal values. There was no difference in the ORFab (open reading frame $\mathrm{AB}$ ) threshold and $\mathrm{N}$ genes, while viral shedding lasted significantly longer in asymptomatic cases (median time 14 days vs 19 days).

IgG levels were higher in symptomatic subjects, and the same was true for all the cytokines, pro and antiinflammatory (18 in total). Moreover, a significant increase in INF- $\gamma$ was only seen in symptomatic patients, in contrast to what was reported by other authors [13].

In a study carried out on 79 asymptomatic cases [15], the laboratory results showed that only 45 cases were in reality "true asymptomatic" subjects, where no abnormalities in the routine blood tests, blood biochemistry and infection-related biomarkers were found.

In general, young age $(<45)$ emerged as a fairly common characteristic among asymptomatic cases in all the studies we have analysed [13]-[15].

The take-home message that can be gleaned from these studies is that COVID-19 infection may occur in some subjects without any signs or symptoms. This might mean the same virus behaves differently depending on the host.

An asymptomatic subject can infect other subjects, who may become symptomatic right up to developing a severe disease. However, deaths are quite rare events in these patients, and may be due to other concomitant diseases exacerbated by the viral infection. In the end, asymptomatic subjects can modulate immunological reactivity, regardless of the variant they have.

This is an important observation, which means asymptomatic subjects are capable of changing a "lethal drift" into a "non-lethal drift". Although the latter can be detected through the usual diagnostic ORFab the clinical outcome may be completely different.

These aspects may be part of host adaptation, which has been a common event in viral infections since their first description in the Middle Ages. In the last 120 years, there have been pandemics in 1889, 1918, 1957, 1968, 1977 and 2009 [16]. The "Spanish flu", in 1918, was the worst pandemic in recorded history since over 50 million people died worldwide [17].

The disease disappeared in the span of two years, as occurred for other pandemics, and we cannot rule out the 
possibility a "non-lethal variant" developed and became prevalent owing to genetic interaction between the host and virus.

The aim of the present research is to consider the ratio positive cases/deaths due to COVID-19 in the European countries on the light asymptomatic subjects and non-lethal drifts.

\section{METHODS}

The data of the European countries were retrieved from the WHO coronavirus dashboard. Italy was taken as example to calculate the differences among Regions in the same country, and the relative data were taken from the Italian Official Bulletin. LEEDELS (life expectancy, ecological, demographical, lifestyle variables) were derived from the Atlante Geografico De Agostini 2020, and CIA World Factbook 2020-2021.

The statistical analysis was based on the ODDS ratio.

\section{RESULTS}

In the case of COVID-19, the ratio between number of cases and number of deaths has been calculated for different parts of the world, as the WHO reports [19]. The data are summarized in Table I.

The differences between different parts of the world are significant, with ratio values of from 15.02 to 24.48 .

Europe was chosen for more detailed analysis: in the 47 countries of the European Council, the ratio values range from between $0.01 \times 10^{3}$ (Norway) to $88.95 \times 10^{3}$ (Andorra) as reported in Table II.

The data of Italy were taken as example of the difference that can be detected among the Regions of the same country. The data are reported in Table III.

The value for Italy is 20.14 per $10^{3}$, which is very close to the European average. However, when the figure is broken down into the 21 Italian regions (Table III), there is an evident large difference between the 16.80 in Sardinia and the 42.09 in Friuli Venezia Giulia, and whitin the Regions there are towns with a ratio which is lower than $4 \times 10^{3}$.

In Europe the correlations between LEEDELS variables (life expectancy, ecological, demographic, lifestyle [20]) was not significant for any of the variables (data not reported), while in Italy the most affected Regions and those with the highest GPD (gross domestic product), the most developed Industrial setting, and living in the flat land or in the mountains [21].

TABLE I: RATIO BETWEEN NUMBER OF POSITIVE CASES AND NUMBER OF DEATHS IN DIFFERENT PARTS OF THE WORLD AS OF 24 MAY 2021

\begin{tabular}{cccc}
\hline Area & Positive cases $(\mathrm{P})$ & Deaths $(\mathrm{D})$ & Ratio D/P $\times 10^{3}$ \\
\hline Americas & 66804131 & 1635868 & 24.48 \\
Europe & 54117388 & 1145899 & 21.17 \\
Southeast Asia & 3122341 & 393895 & 12.61 \\
Eastern & 10019315 & 200656 & 20.04 \\
Mediterranean & 3482292 & 86783 & 24.91 \\
Africa & 2953064 & 44363 & 15.02 \\
Western Pacific & &
\end{tabular}

TABLE III: NUMBER OF CASES, DEATHS AND DEATHS RATIO DUE TO COVID-19 IN THE 20 ITALIAN REGIONS UP TO MAY 24, 2021 [19]

\begin{tabular}{cccc}
\hline Region & N of cases & N of deaths & Ratio $\times 10^{3}$ \\
\hline Lombardia & 8321336 & 33478 & 40.27 \\
Veneto & 422014 & 11530 & 27.32 \\
Piemonte & 426336 & 7102 & 17.06 \\
Campania & 382387 & 13153 & 34.40 \\
Emilia Romagna & 358565 & 11587 & 32.31 \\
Lazio & 339904 & 8101 & 23.83 \\
Toscana & 248829 & 6400 & 25.72 \\
Sicilia & 239719 & 6639 & 27.69 \\
Puglia & 223270 & 5747 & 25.74 \\
Friuli Venezia & 102358 & 4308 & 42.09 \\
Giulia & 102202 & 3006 & 29.47 \\
Marche & 73704 & 2469 & 33.50 \\
Abruzzo & 72605 & 1175 & 16.18 \\
Sardinia & 65951 & 1140 & 17.29 \\
Bolzano & 59449 & 1448 & 24.36 \\
Umbria & 56111 & 1391 & 24.79 \\
Calabria & 45198 & 1354 & 29.69 \\
Trento & 26019 & 570 & 21.91 \\
Basilicata & 13551 & 488 & 36.01 \\
Val d'Aosta & 11540 & 471 & 40.94 \\
Molise & & &
\end{tabular}

TABLE II: NUMBER OF CASES, DEATHS AND DEATHS RATIO DUE TO COVID-19 IN EUROPEAN COUNTRIES UP TO MAY 24 [18]

\begin{tabular}{|c|c|c|c|c|c|c|c|}
\hline Country & $\mathrm{N}$ of cases & $\mathrm{N}$ deaths & Ratio $\times 10^{3}$ & Country & $\mathrm{N}$ of cases & $\mathrm{N}$ deaths & Ratio $\times 10^{3}$ \\
\hline Albania & 132264 & 2447 & 18.50 & Liechtenstein & 3099 & 57 & 18.39 \\
\hline Andorra & 13682 & 1217 & 88.95 & Lithuania & 273346 & 4235 & 15.49 \\
\hline Armenia & 222513 & 4423 & 19.88 & Luxembourg & 69749 & 813 & 11.66 \\
\hline Austria & 639054 & 10317 & 16.14 & Malta & 30520 & 419 & 13.73 \\
\hline Azerbaijan & 333317 & 4891 & 14.67 & Moldova & 254985 & 6903 & 27.07 \\
\hline Belgium & 105543 & 24902 & 23.59 & Monaco & 2503 & 32 & 12.78 \\
\hline Bosnia & 203762 & 91994 & 45.12 & Montenegro & 99469 & 1578 & 15.86 \\
\hline Bulgaria & 417819 & 17637 & 42.21 & The Netherlands & 1637466 & 17592 & 10.74 \\
\hline Croatia & 35567 & 7992 & 22.47 & North Macedonia & 155169 & 5396 & 34.77 \\
\hline Czechia & 1660481 & 30088 & 18.12 & Norway & 124029 & 783 & 0.01 \\
\hline Cyprus & 72159 & 357 & 4.95 & Poland & 2870595 & 73557 & 25.62 \\
\hline Denmark & 277399 & 2511 & 9.05 & Portugal & 847006 & 17022 & 20.10 \\
\hline Estonia & 129297 & 1247 & 9.64 & Romania & 1076840 & 30131 & 27.98 \\
\hline Finland & 92062 & 946 & 10.28 & San Marino & 5090 & 90 & 17.68 \\
\hline France & 5535701 & 108304 & 19.56 & Serbia & 71142 & 6823 & 9.59 \\
\hline Georgia & 3412894 & 4722 & 1.39 & Slovakia & 389440 & 12333 & 31.67 \\
\hline Germany & 3669870 & 88187 & 24.03 & Slovenia & 252848 & 4686 & 18.53 \\
\hline Greece & 396970 & 11955 & 30.12 & Spain & 366167 & 79888 & 21.81 \\
\hline Hungary & 803567 & 29575 & 36.80 & Sweden & 1068474 & 14451 & 13.52 \\
\hline Iceland & 9756 & 30 & 4.46 & Switzerland & 689924 & 10916 & 27.82 \\
\hline Ireland & 259852 & 4941 & 19.01 & Turkey & 5220549 & 46970 & 9.00 \\
\hline Italy & 4205970 & 125793 & 29.91 & Ukraine & 2196673 & 50232 & 22.87 \\
\hline Kosovo & 107293 & 2232 & 20.80 & United Kingdom & 4473681 & 127758 & 28.56 \\
\hline Latvia & 132258 & 2355 & 17.81 & Total deaths in Europe & 50251983 & 1017213 & 20.24 \\
\hline
\end{tabular}




\section{DISCUSSION}

Considering the differences of ratio deaths/positive cases in the European countries some questions are arising:

are we looking at the same virus, or are there different variants with different degrees of lethality?

In the case of different viral characteristics in terms of mortality, we cannot rule out the existence of "non-lethal drifts" going the other way from what is claimed for some variants (e.g., the Kent, Brazilian and Indian), which are considered more invasive and lethal or less sensitive to current vaccines.

Viral replication is extremely high in every living organism, as is the possibility of many variants being generated, from those that are more deadly to those that do not cause any clinically evident disease. If the latter prevail, deaths will disappear.

\section{A. The Possibility of Non-lethal needs some Brief Explanation}

The COVID-19 has been shown to have at least three type of target cells, pneumocytes II which are expressed in the pulmonary alveoli, goblet cells of airways mucosa, and enterocytes [22]. This indicates that the virus can invade the human organism using two of the main gateways of our body and the type of cells that can be aggressed may have different capacity to react. The pattern of the cellular reactivity is unknown, and one may not exclude that they may behave different according to the type of cell, and the viral aggression of the gut may end up with different outcomes than for the alveolar aggression.

The reason of this selectivity belongs to the presence on these cells of a large number of ACE2 receptors and of the enzyme TMPRSS2. The viral Spike protein recognizes the receptor and activate the cell surface protease TMPRSS and the lysosomal protease cathepsins which consent the viral genoma release [23]

One particular characteristic of the virus is that it may have hidden Receptor Binding Domains (RBD)s which can evade the immune surveillance. This last characteristic can justify the existence of variants which can be more lethal because can escape the immune system.

Furthermore, it is known that RNA virus has mutation rates up to a million times higher than their host [24] which are correlated with virulence and evolvability.

Mutation allows the spillover (e.g., (bat/humans), and the adaptation virus/host reduces the mutation to zero, since the virus becomes part of the metaorganism "fitting the landscape".

The reasons why this happens are unknown, and probably have something to do with links between environmental, genetic, and epigenetic variables.

It is known that the high mutation rates yield a viral offspring that differ by 1-2 mutation each from their parents [25]

Experimentally, in Vero cells, the viral growth of the COVID-19 (accession number: MT48758) in 72 hours is three orders of magnitude higher than the initial concentration (MOI 0.5), and one may understand the extremely large number of drifts that can be originated.
The consequence is such that practically every subject infected by the virus can be the source of a variant, and the higher is the mutation the easier will be to find a virus adaptable to the human body.

Since among the viral drifts there are also those more lethal, the cost of the evolution of this very invasive coronavirus will be extremely high, despite the evolutionary law teaches that "the guest death is not convenient for the hosted".

A virus like Ebola that was causing a very high mortality (up to 50\%) and end up with a much more limited diffusion than with COVID-19, which is characterized by an extremely high diffusion just because of the relative limited deaths rate that is causing (about $2 \%$ in the World).

\section{B. The Asymptomatic Subjects}

In more simple terms, the issue of asymptomatic COVID19 subjects brings up at least three possible questions:

a) Are these subjects affected with a particular variant?

b) Are subjects able to modify the virus once it comes into contact with their immune system target cells?

c) Is their immune system able to control the process that modulates the overproduction of cytokines?

The possibility that asymptomatic subjects are capable of modifying the virus and make it less aggressive as a compatible meta-organism is intriguing.

The cases of viral transmission from asymptomatic subjects to other subjects who become fully symptomatic cannot rule this hypothesis out, since several replications may be necessary over time to end up with a non-invasive drift.

This event could be more efficient in some people (children and youths), who are equipped to control the viral aggression and prevent it from reaching a level where it can damage a target organ (mainly, but not only, the lungs).

Since positive swabs can also detect some of the drifts (e.g., the Kent, South African, Brazilian, and Indian variants), they might also be sensitive to a variant that does not cause clinically relevant symptoms or to a non-lethal drift. One may not exclude that non-lethal drifts may escape the common swabs and can be the cause of the reduction of ratio swabs/positive cases.

On the base of these considerations, one may suppose that for the COVID-19 the evolution into a non-mortal drift will be consistent with its apparent disappearance. Vaccinations improving the host defense will accelerate the deaths decrease [26], although one may expect that other more aggressive drifts will emerge occasionally, making the vaccination a common procedure, more or less like for the common influenza.

Even more important will be to find a therapy, making the disease similar to any infection.

These aspects have not been studied carefully, and more attention should be paid to characterizing the virus in asymptomatic subjects.

\section{CONCLUSIONS}

COVID-19 started in China probably in 2019 [27] and was spread through the Europe following a quite defined road map [28]. The asymptomatic subjects can be vectors of the infection due to the extremely high diffusion capacity of this 
virus. Similarly, the formation of many drifts was causing the appearance of lethal and non-lethal drifts, up to the level that some of them could escape the swab sensitivity and the vaccine coverage. Nevertheless, vaccines can reduce the viral replication and diffusion together with the possibility that a non-lethal variant will prevail.

These are the reason of the death decay that it takes place in Europe, which may continue provided that the common hygienic tools (mask, mouthwashes, disinfection, and distance) are maintained.

Due to the large diffusion of the virus, one may expect that it will become part of our metaorganism and will reemerge regularly.

\section{ACKNOWLEDGMENT}

I'm grateful to Prof Martino Recchia (Statmed MilanoItaly) who was making the statistical evaluations.

\section{FINANCIAL SUPPORT}

The research received no financial support.

\section{AUTHOR CONTRIBUTIONS}

UC conceived the trial, retrieved all the data, and wrote the text.

\section{ETHICAL STATEMENT}

This manuscript is original, has not been published before, and is not being considered for publication elsewhere. All the authors mentioned in this manuscript have agreed on its authorship, read, and approved it, and given their consent for its submission and subsequent publication.

\section{REFERENCES}

[1] V'kovski P, Kratzei A, Steiner S et al. Coronavirus biology and replication: implication for SARS-Cov-2. Nature Microbiology 2021; 19: $155-169$.

[2] Morens DM, Brema JC, Calisher CH et al. The origin of COVID-19 and why it matters. Am J Trop Med Hyg 2020; 103(3): 955-959.

[3] Cheng VCC, Lau SKP, Woo PCY, Yuen KY. Severe acute respiratory syndrome coronavirus as an agent of emerging and reemerging infection. Clin Microb Rev 2007: 2(4): 660-694.

[4] Alagalli AN, Briese T, Mishra $\mathrm{N}$ et al. Middle East respiratory syndrome coronavirus infection in dromedary camels in Saudi Arabia. mBio 5:e00884-14-e00814. http://doi.org/10.1128/mBio.00884-14.
[5] Ithete NL, Stroffberg S, Coman VM et al. Close relative of human Middle East respiratory syndrome coronavirus in bat. South Africa Emerg Infect Dia 2013,19: 1697-1699.

[6] Woo PC, lau SK, Yip CC et al. Comparative analysis of 22 coronavirus HKU1 genomes reveals a novel genotype and evidence of natural recombination in coronavirus HKU1. J Virol 2006; 80: 7136-7145.

[7] Zhu N, Zhang D, Wang W et al. A novel coronavirus from patients with pneumonia in China, 2019. NEJM 2019: 382: 727-733.

[8] Cao S, Gan Y, Wang C et al. Post-lockdown SARS-Cov-2 nucleic acid screening in nearly 10 million resident of Wuhan, China. Nat Commun 2020; https://doi.org/10.1038/s41467-020-19802-w.

[9] Pollock AM, Lancaster J. Asymptomatic transmission of covid-19. BMJ 2020; 371: m4851http://dx.doi.org/10.1136/bmj.m4851.

[10] Bultrago-Garcia D, Egil-Gany D, Counotte MJ et al. Occurrence and transmission potential of asymptomatic and presymptomatic SARSCov-2 infection: a living systematic review and meta-analysis. Plos Medicine 2020 http://doi.org/10.1371/8journal.pmed.1003346.

[11] Zhou X, Li Y, Li T, Zhang W. Follow-up of asymptomatic patients with SARS-CoV-2 infection. Clin Microb Infect 2020; 26:957-959.

[12] Chen G, Wu D, Guo W et al. Clinical and immunological features of severe and moderate coronavirus disease 2019. J Clin Invest 2020;130(5): 2620-2629.

[13] Stephenson E, Reynolds G, Botting RA et al. Single-cell multi-omics analysis of the immune response in COVID-19. Nature Medicine 2021;27: 904-914.

[14] Long QX, Tang KJ, Shi QL et al. Clinical immunological assessment of asymptomatic SARS-Cov-2 infection. Nature Medicine 2020;26: 1200-1204.

[15] Yu C, Zhou M, Liu Y et al. Characteristics of asymptomatic COVID19 infection and progression: a multicenter, retrospective study. Virulence 2020; 11. 1006-1014.

[16] Tauemberg JK, Morens DM. Pandemic influenza-including a risk assessment of H5N1. Rev Sci Tech 2009; 28: 187-202.

[17] Johnson NP, Mueller J. Updating the accounts: global mortality of the 1918-1920 "Spanish" influenza pandemic. Bulletin of the history of medicine. 2002; 76: 105-115.

[18] World Health Organization WHO Dashboard http://covid 19 who.int.

[19] Bollettino Coronavirus protezione Civile https://www.lavoripubblici.it/news/ultime-notizie-covid-19bollettino-protezione-civile-24-maggio-2021-html.

[20] Cornelli U, Belcaro G, Recchia M. COVID-19 vaccination: hopes and facts to cover incompetence. J Bacteriol \& Parasitol 2021; 12(3):1-22.

[21] Cornelli U, Belcaro G, Cesarone MR, Recchia M, Cotellese R. Cov19 in Italy: correlation with Clinical, demographical, social variables and water. JMCRR 2020; 4(6): 1-10.

[22] Ziegler CG, CaoY, Guo Z et al. SARS-Cov-2 receptor is an interferonstimulated gene in human airways epithelial cells and is detected in specific cell subsets across tissues. Cell 2020;181:1-20.

[23] Shang J, Wan Y, Luo C et al. Cell entry mechanisms o SARRS-CoV2PNAS 2020;117: 117241-11734.

[24] Duffy S. Why are RNA virus mutation so damn high? PLOS biology 2018;16(8): e3000003.https//doi. Org.10.137/jpurnal.pbio.3000003.

[25] Vignuzzi M, Andino R. Closing the gap: the challenges in convering theoretical, computational, experimental and real-life studies in virus evolution. Curr Opin Virol 2012; 2(5): 515-518.

[26] Cornelli U, Belcaro G. The effect of COVID-19 vaccination in 47 European countries. EJMED (in press).

[27] Wu A, Peng Y, Huang B et Al. Genome composition and divergence of the novel coronavirus (2019-nCov) originating in China. Cell Host \& Micr 2020 https//doi.org10.1016/j.chom2020.02.001.

[28] Cornelli U, Belcaro G, Martino R. The many waves of COVID-19 in European Countries. 2021 Lampert Academic Publishing. 